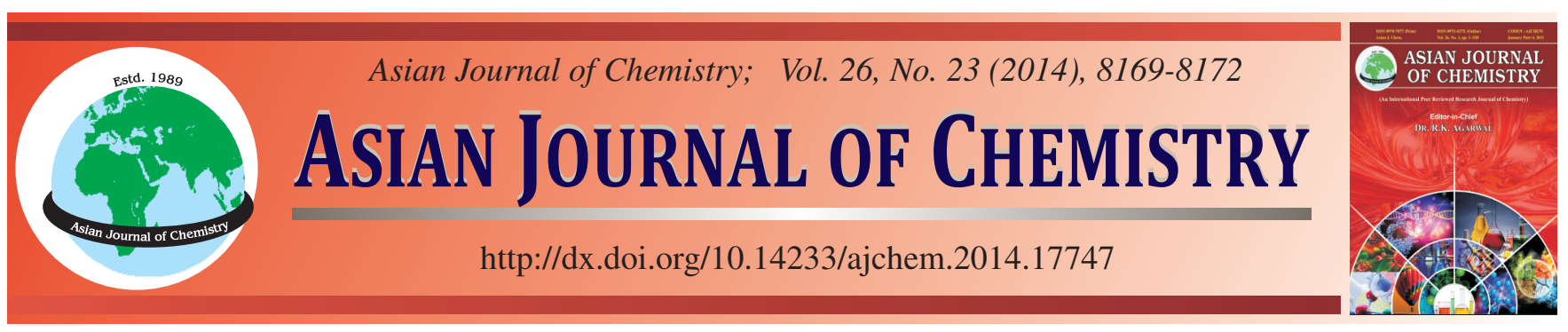

\title{
Determination of DPPH Free Radical Scavenging Activity of Polyphenolic Compounds in Terminalia by HPLC
}

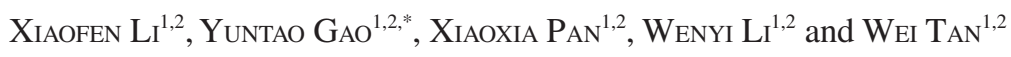

${ }^{1}$ School of Chemistry and Biotechnology, Yunnan University of Nationalities, Kunming 650031, Yunnan Province, P.R. China

${ }^{2}$ Key Lab of National Medicine Supported Jointly by State Ethnic Affairs Commission and Ministry of Education, Yunnan University of Nationalities, Kunming 650031, Yunnan Province, P.R. China

*Corresponding author: Tel: +86 13888610792; E-mail: yuntaogao@sohu.com

The spectrophotometric method for the evaluation of 1,1-diphenyl-2-picrylhydrazyl (DPPH') free radical scavenging activity has certain shortcomings such as like interference from color pigments from natural products and lower sensitivity. A specific HPLC method for evaluating the DPPH free radical scavenging activity of natural products was developed. A gradient elution method was employed to obtain better efficiency of separation. The best chromatographic conditions are as follows. The mobile phase was a mixture of methanol and water $(50: 50, \mathrm{v} / \mathrm{v})$ pumped at a flow rate of $1 \mathrm{~mL} / \mathrm{min}$, the DPPH peaks were monitored at $517 \mathrm{~nm}$ and the column temperature was $25^{\circ} \mathrm{C}$. The proposed HPLC method was applied for the estimation of DPPH free radical scavenging activity of polyphenolic compounds such as gallic acid, vanillic acid, caffeic acid, $p$-coumaric acid and rutin and the extract of Terminalia. The $50 \%$ radical scavenging activity $\left(\mathrm{IC}_{50}\right)$ determined by the HPLC method correlated well with that of spectrophotometry. The HPLC method can be used as a reliable method of estimate the antioxidant activity for natural products.

Keywords: Antioxidants, HPLC, DPPH free radical, Polyphenolic compounds, Terminalia.

\section{INTRODUCTION}

Herbs are used in many domains, including medicine, nutrition, flavouring, beverages, dyeing, repellents, fragrances, $\operatorname{cosmetics}^{1-2}$. Herbal medicine plays an important role in clinical therapy and is widely accepted as an alternative therapy, owing to its unmatched chemical diversity and minimum side effects. Terminalia is a well-known crude drug and a key herb ingredient in many important multi-herb remedies in traditional Chinese medicine (TCM) and it has been used for hundreds of years in China and other countries ${ }^{3}$. Polyphenolic compounds are commonly found in both edible and inedible plants and they have been reported to have multiple biological effects, including antioxidant activity ${ }^{4,5}$. Pharmacological studies revealed that polyphenolic compounds including gallic acid, vanillic acid, caffeic acid, $p$-coumaric acid were the main active components in Terminalia and all of them have strong antioxidative activities ${ }^{6,7}$. The reports from some publications showed that polyphenolic compounds had various pharmacological properties and could be used as antibacterial, antiinflammatory, antioxidant, anticancer ${ }^{8}$. Polyphenolic compounds in herbs can effectively prevent cerebrovascular and cardiovascular diseases and protect organism from oxidative damages due to their strong antioxidants activity ${ }^{9-12}$.

$\mathrm{DPPH}^{\circ}$ as a stable synthetical free radical species is often used for the evaluation of the general radical scavenging capabilities of various antioxidants ${ }^{13-16}$. Traditional spectrophotometry estimation method of DPPH scavenging effect is based on its strong spectral absorption band at $517 \mathrm{~nm}$ in methanol ${ }^{17}$. The spectrophotometry is used widely in the estimation of DPPH radical scavenging capabilities, but it is not applicable to evaluate the antioxidant activity of colored botanical extracts with a spectral absorption band near $517 \mathrm{~nm}$ due to interference by pigments ${ }^{18-20}$. Therefore, it is necessary to develop more reliable methods for evaluating the DPPH scavenging activitiy of herbal medicine.

Chandrasekar et al..$^{21,22}$ and Keleva et $a l . .^{23}$ developed a HPLC method to evaluate DPPH free radical scavenging activity of synthetic drugs. Compared with spectrophotometry, HPLC method can effectively separated sample from interfering substances with higher accuracy and reliability. In this paper, DPPH free radical scavenging activities of polyphenolic compounds was investigated using HPLC method. The gradient elution was applied to improve chromatographic peaks of 
DPPH and eliminate the chromatography interference of other ingredients in the botanical extracts. The DPPH free radical scavenging capacity was quantified based on the linearity regression of antioxidant concentration and DPPH free radical scavenging rate. And the proposed method was used to determinate the antioxidant of Terminalia polyphenols. The purpose of this paper was to develop a HPLC method specific for the determination of the DPPH free radical scavenging activities of polyphenolic compounds in herb medicine.

\section{EXPERIMENTAL}

DPPH (the purity higher then $99 \%$ ) was obtained from Sigma. Gallic acid, vanillic acid, caffeic acid, $p$-coumaric acid and rutin (used as reference substance, the purity higher then $99 \%$ ) were purchased from National Institute of China for the Control of Pharmaceutical and Biological Products (NICPBP, Bejing, China). Methanol (HPLC-grade) was from Tedia (Fairfield, $\mathrm{OH})$. All aqueous solutions were prepared with purified water (Wahaha, Hangzhou, China).

Sample preparation: The DPPH and all standard antioxidants including extracts of Terminalia were soluble in methanol. Fresh DPPH stock solution $(10 \mathrm{~mL})$ at a concentration of $2 \mathrm{mM} / \mathrm{L}$ was prepared on each day of analysis. The stock solutions of gallic acid, caffeic acid, rutin and extracts of Terminalia were prepared in methanol at a concentration of $1 \mathrm{mg} / \mathrm{mL}$. The stock solutions of vanillic acid and $p$-coumaric acid were prepared in methanol at a concentration of $50 \mathrm{mg} / \mathrm{mL}$ and stored at $-20^{\circ} \mathrm{C}$. An aliquot of $10 \mu \mathrm{L}$ of different concentrations of standard antioxidants or extracts of Terminalia in methanol were added to $100 \mu \mathrm{L}$ of DPPH in solution (final concentration $1 \mathrm{mM} / \mathrm{L})$. The mixture was vortexed for few seconds and left to stand in the dark for $30 \mathrm{~min}$ at room temperature.

HPLC analysis: The sample is filtered through $0.2 \mu \mathrm{m}$ nylon membrane filter (Pall Gelman Laboratory, USA) and
$20 \mu \mathrm{L}$ of the sample is injected for HPLC analysis. The blank was prepared by adding $100 \mu \mathrm{L}$ of methanol to $100 \mu \mathrm{L}$ of DPPH stock Solution (final concentration $1 \mathrm{mM} / \mathrm{L}$ ) and included before each run. Agilent1200 series high performance liquid chromatograph system (Aglient Technologies, USA), equipped with DAD diode array detector (G1315A), quaternary pump (G1311A), automatic sampler (SIL-10AP), UV variable-wavelength detector (1314A-UV) and column oven (CTO-10ASVP). The analysis column was a XDB- $\mathrm{C}_{18}$ column $(150 \times 4.6 \mathrm{~mm}$, i.d, $5 \mu \mathrm{m})$ maintained at $25^{\circ} \mathrm{C}$. The mobile phase consisted of methanol (A) and $\mathrm{H}_{2} \mathrm{O}(\mathrm{B})$. A linear gradient of mobile phase $\mathrm{A}$ was applied during the analysis. The gradient profile was as follows: $0-15 \min (50 \% \mathrm{~A}), 15-20 \mathrm{~min}(90 \%$ A). The flow rate of mobile phase was $1 \mathrm{~mL} \mathrm{~min}^{-1}$. The injection volume was $20 \mu \mathrm{L}$. The DPPH peaks were monitored at 517 $\mathrm{nm}$. The difference in the reduction of DPPH peak area (PA) between the blank and the sample was used for determining the percent radical scavenging activity of the sample.

Radical scavenging $(\%)=\left[\mathrm{PA}_{\mathrm{BLANK}}-\mathrm{PA}_{\mathrm{SAMPLE}}\right] / \mathrm{PA}_{\mathrm{BLANK}} \times 100 \%$

\section{RESULTS AND DISCUSSION}

Optimization of mobile phase: In the present work, the gradient elution was used in HPLC method. As DPPH was soluble in methanol, for HPLC mobile phase optimization different ratios of methanol and water including 50:50, 70:30 and 80:20 (v/v) were examined. When the methanol content was $20 \%$, DPPH retention time was too short and the peak shape is not so better, DPPH retention time was found to decrease on increasing the organic phase content. DPPH eluted as a sharp peak at $14.955 \mathrm{~min}$ when the mobile phase ratio was 50:50. The method was specific for DPPH with a run time of $20 \mathrm{~min}$. Good resolution and symmetrical peak shape was obtained as shown in Fig. 1a, which indicating that the
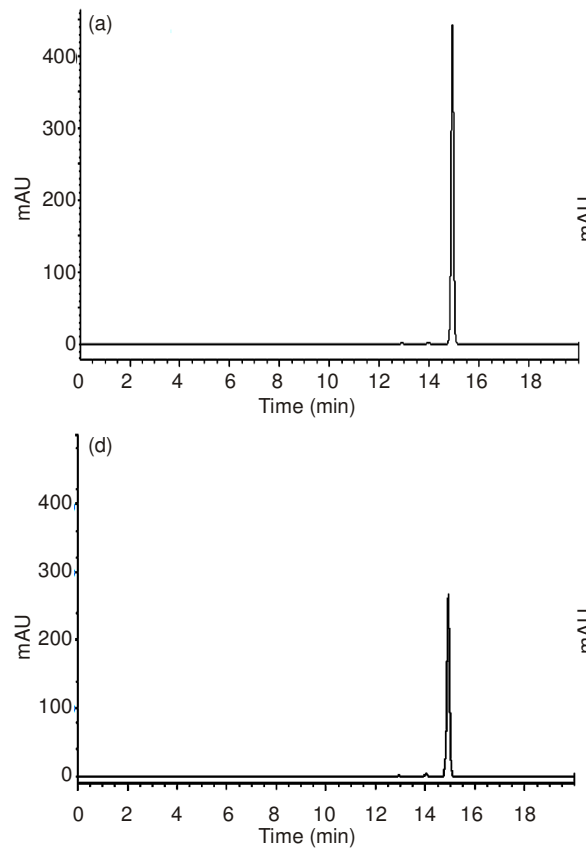
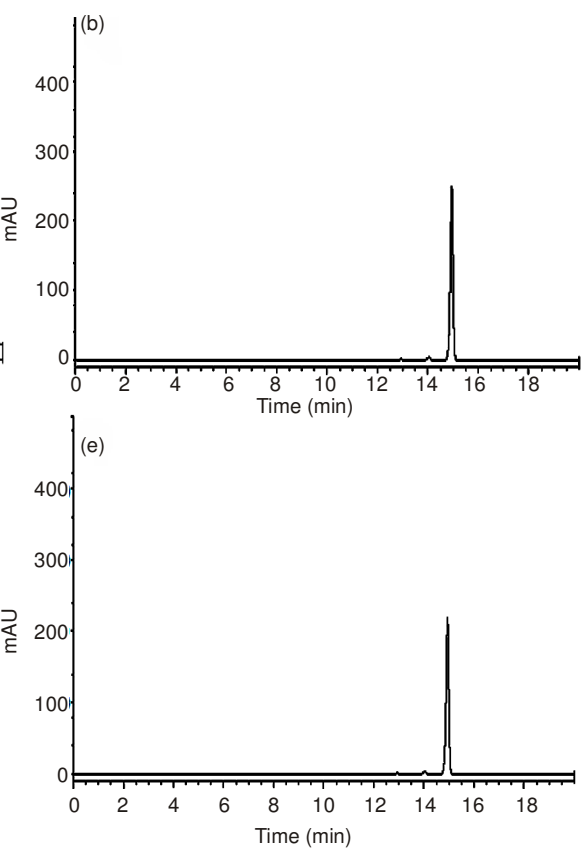
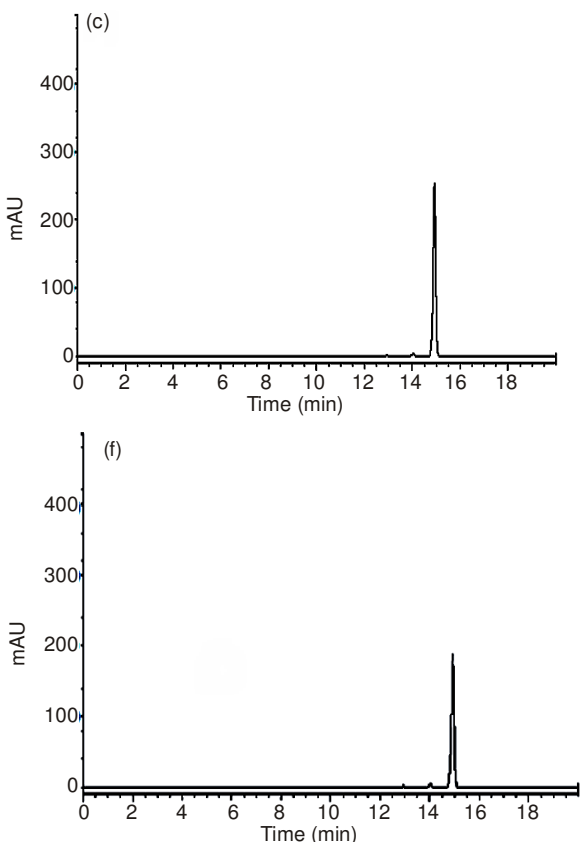

Fig. 1. (a) Blank and after incubation with; (b) gallic acid $10 \mu \mathrm{L}$; (c) caffeic acid $30 \mu \mathrm{L}$; (d) vanillic acid $30 \mu \mathrm{L}$; (e) p-coumaric acid $150 \mu \mathrm{L}$ and (f) pure extracts of terminalia $40 \mu \mathrm{L}$. HPLC conditions: column, a Agilent1200 XDB-C $\mathrm{C}_{18}(4.6 \times 150 \mathrm{~mm}$ i.d, $5 \mu \mathrm{m})$ column; mobile phase, a mixture of methanol and water $(50: 50, \mathrm{v} / \mathrm{v})$; flow rate, $1 \mathrm{~mL} / \mathrm{min}$; detection wavelength, $517 \mathrm{~nm}$; column temperature, $25^{\circ} \mathrm{C}$; injection volume, $20 \mu \mathrm{L}$ 
peak was well separated and the chromatography interferences of other ingredients in the Terminalia extracts was eliminated by the gradient elution method.

As shown in Fig. 1a, the HPLC chromatograms of DPPH blank solution with the concentration of $1 \mathrm{mM} / \mathrm{L}$ (as the blank). As gallic acid, caffeic acid, vanillic acid, $p$-coumaric acid and pure extracts of Terminalia was addition into DPPH blank solution, respectively, the peak area of DPPH was decreased obviously, the peak area and four polyphenolic compounds have dose-response relationship, which indicated that the proposed HPLC can be used to estimate the DPPH free radical scavenging activity of polyphenolic compounds.

Repeatability and reproducibility: The repeatability and reproducibility of the analytical method was confirmed from the peak area and retention times of the DPPH blank solution. The results as listed in Table-1, indicated good repeatability and inter-day precision with acceptable RSD (<4\%).

\begin{tabular}{|c|c|c|c|c|}
\hline & \multicolumn{4}{|c|}{$\begin{array}{c}\text { TABLE-1 } \\
\text { REPEATABILITY AND REPRODUCIBILITY OF } \\
\text { THE RETENTION TIME AND PEAK AREA } \\
\text { OF DPPH BLANK SOLUTION }(\mathrm{n}=6)\end{array}$} \\
\hline & Retention time (min) & RSD (\%) & Peak area & RSD (\%) \\
\hline \multirow{6}{*}{ Day 1} & 14.955 & \multirow{6}{*}{0.25} & 3049 & \multirow{6}{*}{3.8} \\
\hline & 14.937 & & 2951 & \\
\hline & 14.931 & & 3250 & \\
\hline & 14.926 & & 3247 & \\
\hline & 14.886 & & 3101 & \\
\hline & 14.856 & & 3189 & \\
\hline \multirow{6}{*}{ Day 2} & 14.931 & \multirow{6}{*}{0.18} & 3047 & \multirow{6}{*}{4.0} \\
\hline & 14.918 & & 2940 & \\
\hline & 14.95 & & 3054 & \\
\hline & 14.923 & & 3205 & \\
\hline & 14.876 & & 3280 & \\
\hline & 14.951 & & 3189 & \\
\hline \multirow{6}{*}{ Day 3} & 14.942 & \multirow{6}{*}{0.15} & 3263 & \multirow{6}{*}{2.9} \\
\hline & 14.922 & & 3031 & \\
\hline & 14.924 & & 3200 & \\
\hline & 14.891 & & 3245 & \\
\hline & 14.882 & & 3078 & \\
\hline & 14.899 & & 3124 & \\
\hline
\end{tabular}

Linearity graphs of standard antioxidants: The linearity regression of antioxidant concentration and DPPH free radical scavenging activity was tested (Table-2). Good linear correlation for all antioxidants was obtained. In addition, the $50 \%$ radical scavenging activity $\left(\mathrm{IC}_{50}\right)$ of the antioxidants can be calculated based on the calibration equation as showed in Table-3. Because lower $\mathrm{IC}_{50}$ value means high radical scavenging activity, the radical scavenging activity was ranked as follows: gallic acid $>$ caffeic acid $>$ extracts of Terminalia $>$ rutin $>$ vanillic $>p$-coumaric acid.

\begin{tabular}{lccl}
\multicolumn{5}{c}{ TABLE-2 } \\
\multicolumn{4}{c}{$\begin{array}{c}\text { LINEARITY GRAPH OF STANDARD } \\
\text { ANTIOXIDANTS BY HPLC METHOD }\end{array}$} \\
\hline \multicolumn{1}{c}{ Standards } & $\begin{array}{c}\text { Calibration } \\
\text { equation }\end{array}$ & $\begin{array}{c}\text { Correlation } \\
\text { coefficient }(\mathrm{r})\end{array}$ & $\begin{array}{c}\text { Linear range } \\
(\mathrm{mg} / \mathrm{mL})\end{array}$ \\
\hline Gallic acid & $\mathrm{y}=3507.4 \mathrm{x}+4.3541$ & 0.9927 & $0.0025-0.025$ \\
Caffeic acid & $\mathrm{y}=1386.7 \mathrm{x}+6.1953$ & 0.9889 & $0.005-0.06$ \\
Vanillic acid & $\mathrm{y}=24.286 \mathrm{x}+6.7143$ & 0.9653 & $0.5-3.0$ \\
$p$-Coumaric acid & $\mathrm{y}=4.8386 \mathrm{x}+7.7857$ & 0.9628 & $2.5-15$ \\
Rutin & $\mathrm{y}=709.79 \mathrm{x}+8.2867$ & 0.9861 & $0.01-0.12$ \\
$\begin{array}{l}\text { Extracts of } \\
\text { Terminalia }\end{array}$ & $\mathrm{y}=1285.7 \mathrm{x}+4.0000$ & 0.9893 & $0.01-0.07$ \\
\hline
\end{tabular}

\begin{tabular}{|c|c|c|c|}
\hline $\begin{array}{l}\text { FREE RAD } \\
\text { OF ANTIOXID }\end{array}$ & $\begin{array}{r}\text { TABLE- } \\
\text { ICAL SCAVEI } \\
\text { ANTS AND EX }\end{array}$ & $\begin{array}{l}\text { GING ACT } \\
\text { TRACT OF }\end{array}$ & $\begin{array}{l}\text { VITY } \\
\text { Terminalia }\end{array}$ \\
\hline Antioxidants $(\mathrm{mg} / \mathrm{mL})$ & $\begin{array}{c}\mathrm{IC}_{50} \\
\text { concentration } \\
(\mathrm{mg} / \mathrm{mL})\end{array}$ & $\begin{array}{c}\text { Maximum } \\
\text { clearance } \\
\text { rate }(\%)\end{array}$ & $\begin{array}{l}\text { Concentration of } \\
\text { antioxidants } \\
(\mathrm{mg} / \mathrm{mL})\end{array}$ \\
\hline Gallic acid & 0.013 & 93.4 & 0.035 \\
\hline Caffeic acid & 0.032 & 93.5 & 0.080 \\
\hline Vanillic acid & 1.800 & 85.0 & 0.500 \\
\hline$p$-Coumaric acid & 8.700 & 80.0 & 25.000 \\
\hline Rutin & 0.058 & 94.0 & 0.140 \\
\hline Extracts of Terminalia & 0.035 & 93.0 & 0.090 \\
\hline
\end{tabular}

The DPPH radical scavenging activity of the antioxidants can also be evaluated via the comparison of the slope of their calibration equation. According to the calibration equation showed in Table-2, the DPPH radical scavenging activity was listed as follows: gallic acid $>$ caffeic acid $>$ extracts of Terminalia $>$ rutin $>$ vanillic $>p$-coumaric acid, which was agreement with the result from $\mathrm{IC}_{50}$. According to $\mathrm{IC}_{50}$ and the slope of calibration equation, gallic acid and caffeic acid exhibit high radical scavenging activity as comparison with rutin, an acknowledged antioxidant. Gallic acid and caffeic acid are the main active components in Terminalia, so we could expected pure extracts of Terminalia have strong antioxidative activities.

Determination of $\mathbf{I C}_{\mathbf{5 0}}$ values: The $50 \%$ radical scavenging activity $\left(\mathrm{IC}_{50}\right)$ of the antioxidants and extracts of Terminalia is given in Table-3. Based on the $\mathrm{IC}_{50}$ values calculated from the calibration equation of various antioxidants, the $\mathrm{IC}_{50}$ value of the antioxidants and extracts of Terminalia were 0.013 , $0.032,1.8,8.7,0.058$ and $0.035 \mathrm{mg} / \mathrm{mL}$, respectively. As Fig. 2 showed, the maximum scavenging rate was ranked as follows: rutin $(0.14 \mathrm{mg} / \mathrm{mL})>$ gallic acid $(0.035 \mathrm{mg} / \mathrm{mL})>$ caffeic acid $(0.08 \mathrm{mg} / \mathrm{mL})>$ extracts of Terminalia $(0.09 \mathrm{mg} / \mathrm{mL})>$ vanillic $(0.5 \mathrm{mg} / \mathrm{mL})>p$-coumaric acid $(25 \mathrm{mg} / \mathrm{mL})$.
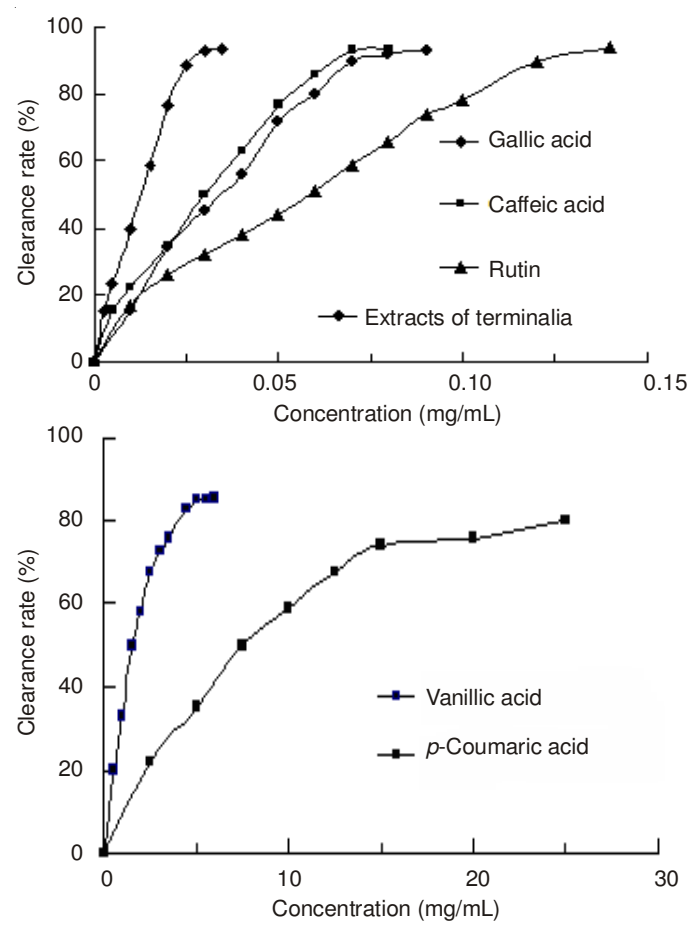

Fig. 2. Clearance rate of four polyphenolic compounds and rutin to DDPH free radicals 


\section{Conclusion}

An HPLC method with good reliable and high reproducibility was developed specific for the determination of the DPPH free radical scavenging activities of polyphenolic compounds in herb medicine. Compared with the pre-existing HPLCDPPH method, the proposed method improved peak shape and efficiency of separation and eliminated the chromatography interference of other ingredients in the Terminalia extracts by the gradient elution. And the results were more accurate and reliable. The DPPH radical scavenging activity of herb medicines can be evaluated via the comparison of the slope of their calibration equation and the $50 \%$ radical scavenging activity $\left(\mathrm{IC}_{50}\right)$ of the antioxidants can be calculated based on the calibration equation. The $\mathrm{IC}_{50}$ values determined by the HPLC method agreed well with those by spectrophotometry. The proposed method can be used as alternative approaches of spectrophotometry in order to get more accurate results. HPLC method was successfully applied for the determination of antioxidant activity of polyphenolic compounds and it has potential application value in evaluating the antioxidant activities of traditional herb medicine.

\section{ACKNOWLEDGEMENTS}

The authors thank the Director, for his encouragement and support for the present investigation. The authors also gratefully acknowledged the financial support by Yunnan Province Scientific and Technological Project for Social Development, grant No. 2007B148M and the Key Lab of National medicine Supported Jointly by state Ethnic Affairs commission and Ministry of Education, grant No. MJY07010 and the Applied Basic Research Project of Yunnan Province Youth Program, 2012FD039.

\section{REFERENCES}

1. A. Djeridane, M. Yousfi, B. Nadjemi, D. Boutassouna, P. Stocker and N. Vidal, Food Chem., 97, 654 (2006).

2. X. Tian, Y.H. Song, H.M. Dong and B.X. Ye, Biol. Electrochem., 73, 18 (2006).
3. L. Song, Modern Dictionary of Chinese Traditional Medicine, People's Medical Publishing House, Beijing, 65, 165 (2001).

4. M.P. Kahkonen, A.I. Hopia, H.J. Vuorela, J.-P. Rauha, K. Pihlaja, T.S. Kujala and M. Heinonen, J. Agric. Food Chem., 47, 3954 (1999).

5. A. Wojdylo, J. Oszmiañski and R. Czemerys, Food Chem., 105, 940 (2006).

6. H.G. Anwarul, K. Arif-ullah, A. Tuba and A. Saad, J. Endocrinol., 116, 528 (2008).

7. A. Bharani, A. Ganguly and K.D. Bhargava, Int. J. Cardiol., 49, 191 (1995).

8. B. Pfundstein, S.K. El Desouky, W.E. Hull, R. Haubner, G. Erben and R.W. Owen, Phytochemistry, 71, 1132 (2010).

9. T. Okuda, Antioxidant in Herbs: Polyphends, Antioxidant Food Supplements in Human Health, People's Medical Publishing House: Beijing, pp. 39-45 (1999).

10. M. Ellnain-Wojtaszek and G. Zgórka, J. Liq. Chromatogr. Rel. Technol., 38, 1457 (1999).

11. C.R. Caldwell, J. Agric. Food Chem., 51, 4589 (2003).

12. G. Cao, E. Sofic and R.L. Prior, J. Agric. Food Chem., 44, 3426 (1996).

13. W. Brand-Williams, M.E. Cuvelier and C. Berset, Lebenson. Wiss. Technol., 28, 25 (1995).

14. S.Y. Zheng, T. F. Chen and W.J. Zheng, Spectrosc. Spect. Anal., 30, 2417 (2010).

15. Y.B. Zhang, W.J. Zheng and Z. Hhuang, Spectrosc. Spect. Anal., 30, 1866 (2010).

16. L.Z. Lin and M.M. Zhao, Food Chem., 31, 63 (2010).

17. O.I. Arouma, B. Halliwell and G. Williamson, in eds: I. Arouma and S.L. Cuppett, Antioxidant Methodology, AOCS Press, IL, USA, p. 173, 204 (1997).

18. T. Yamaguchi, H. Takamura, T. Matoba and J. Terao, J. Biosci. Biotech. Biochem., 62, 1201 (1998).

19. N. Karunakar, M.C. Prabhakar and D.R. Krishna, Arzneimittelforschung-Drug Res., 53, 254 (2003).

20. S.B. Kedare and R.P. Singh, J. Food Sci. Technol., 48, 412 (2011).

21. D. Chandrasekar, K. Madhusudhana, S. Ramakrishna and P.V. Diwan, J. Pharm. Biomed. Anal., 40, 460 (2006).

22. P. Krishnaiah, V.L.N. Reddy, G. Venkataramana, K. Ravinder, M. Srinivasulu, T.V. Raju, K. Ravikumar, D. Chandrasekar, S. Ramakrishna and Y. Venkateswarlu, Nat. Prod. Phytochem. Anal., 67, 1168 (2004).

23. I.I. Koleva, T.A. van Beek, J.P.H. Linssen, A. Groot and L.N. Evstatieva, Phytochem. Anal., 13, 8 (2002). 